\title{
The History of Science and the History of Knowledge
}

LORRAINE DASTON, UNIVERSITY OF CHICAGO

$\mathrm{H}$ ISTORIANS OF SCIENCE are caught in a hall of mirrors whenever we try to reflect on how we know what we know and why what we know is worth knowing. At one level, we confront this question just as any other discipline would: What are our sources and standards of evidence? Acceptable forms of argument? Criteria for a significant topic and a satisfactory explanation? But at another level-indeed, a mise-en-abîme of further levels-we are the discipline charged with historicizing just such questions about the how, what, and wherefore of knowledge: What counts as knowledge in a given epoch and culture and why? How do classifications and hierarchies among kinds of knowledge (say, theology and mathematics in thirteenth-century Paris, or Confucian ethics and silk manufacture in Ming dynasty China, or the sciences and the humanities right now) reshuffle? How do new ways of knowing - the controlled experiment, constructing a genealogy in historical philology or evolutionary biology, error analysis-emerge, and how are they braided together with older methods into a stronger rope of infer- 
ence? At this point, the vertigo of all those reflections within reflections sets the mind spinning.

At the risk of infecting the reader with our disciplinary dizziness, I would nonetheless like to sustain double vision in this essay about how the history of science is becoming, haltingly and hesitatingly, the history of knowledge-and why this is happening now. Section I describes how the history of science became a discipline and how its origins molded assumptions about what science is, who has it, and why its history matters. This is a history recent enough for historians of science of my generation (i.e., PhD circa I980) to have experienced mostly firsthand. Section II turns to the history of knowledge, an emergent field (not yet a discipline): What is it, what could it be, and what is its relationship to the history of science?

\section{Why Is There a Discipline Called the History of Science?}

The history of science is almost as old as science itself, but the discipline of the history of science is barely a century old. Since Aristotle reviewed the theories (and errors) of his predecessors in the Physics, brief, name-dropping, and usually highly tendentious accounts of the views of one's predecessors (once called doxographies, now known as "reviews of the literature") have remained a standard component of the treatise, the textbook, the dissertation, and the scientific and scholarly article. These lineages serve any number of functions, from inserting the author into a pedigree that stretches back to past luminaries (particularly strong among mathematicians and philosophers, who imagine their traditions in the form of family trees and are still in ouija-board-like communication with the likes of Euclid and Kant) to glamorizing the topic by august association ("since Kepler astronomers have puzzled over the spacing of the planets ...") to simply reculer pour mieux sauter. But all of them are in bad odor among pro- 
fessional historians of science, a group that barely existed before the mid-twentieth century.

The discipline of the history of science, which frowns upon pressing science past into the service of science present, established itself in academic departments, centers, and programs in Europe and North America in the I950s and 6os. ${ }^{\mathrm{I}}$ This wave of institutionalization was largely a response to the whirlwind transformations wrought by technoscience in transportation, communication, industry, and warfare-and to the claim, advanced in a handful of influential books published from roughly I920 to I960 in English, French, and German, that science was the motor of capital-M Modernity. Despite their persnicketiness about recasting premodern science into modern scientific terms, professional historians of science owe the very existence of their discipline to books with teleological titles such as Science and the Modern World (I925) and The Origins of Modern Science (I949). ${ }^{2}$ The argument was simple and, judging from the print runs and worldwide translations of these books, is still powerful: science created the modern world and with it Western geopolitical dominance; anyone who wanted to understand how modernity came about and how to deal with its challenges must therefore understand the history of science. This message became screamingly urgent, at latest, with the detonation of atomic bombs over Hiroshima and Nagasaki in August 1945. It is no accident that the moving spirit behind one of the largest and most influential departments of the history of science, chemist and Harvard University President James Bryant Conant, had been a high-level administrator of the Manhattan Project.

There were several oddities about the narratives that created the discipline of the history of science. ${ }^{3}$ For one thing, although these books appeared in two waves, the first in the decade after World War I in the I920s and the second after World II in the late I940s and early 50s, there was barely a mention of the hideous new weapons science had produced at the military's behest: neither the poison 
gas concocted by the chemists (Conant himself had been involved in such efforts during World War I) nor the atomic bomb constructed by the physicists merit even a passing reference. For another, the "modern" science in question was not the technoscience of the late nineteenth and early twentieth centuries, which had joined forces with industrial capitalism to produce the sort of new technologies that had enthralled the visitors to the 1893 Columbian Exposition in Chicago or the I900 Exposition Universelle in Paris. No, in these books, "modern" science was projected backward in time to the seventeenth century: it was not the science of Einstein, whose theory of general relativity had just been spectacularly confirmed in I9I9, but rather the science of Galileo and Newton that had allegedly forged modernity. Moreover, the essence of scientific modernity was not power over nature but something called "the modern mentality": a hard-edged rationality that demanded the renunciation of childish illusions and egoism, chief among them the conviction of being the hub of the universe, both literally and figuratively. Finally, modern science had happened first in Europe and catapulted this previously backward, benighted continent to a position of world economic, political, and intellectual dominance. But although its origins were culturally specific, modern science was exportable.

All the authors of these narratives were unanimous that the Scientific Revolution of early modern Europe represented a historical transformation of the first magnitude, as great an event as the flowering of ancient Greece or the advent of Christianity, beside which the Renaissance and Reformation were reduced to "mere episodes." Its reverberations were still echoing all over the globe: "Modern science was born in Europe, but its home is the whole world." ${ }^{5}$ Wherever science spread, modernity arrived in its wake, an irresistible destructive and creative force. This vision of the Scientific Revolution as the Great Divide separating the West from the Rest-and of scientific modernity as a competition of civilizations-spread well beyond 
the history of science. MIT economist Walter W. Rostow, whose views on industrial development shaped American foreign policy from the Kennedy through the Reagan administrations, divided all cultures, past and present, into pre- and post-Newtonian: "In terms of history then, with the phrase 'traditional society' we are grouping the whole pre-Newtonian world: the dynasties in China; the civilization of the Middle East and the Mediterranean; the world of medieval Europe." Note that it is the Scientific Revolution, not the Industrial Revolution, that marks the advent of even economic modernity-and note also how Rostow conflated the European past with the present of almost all other cultures. If history had a Richter scale, the Scientific Revolution would register at 9.0.

These founding narratives (and the post-World War II context that made them so compelling) imparted a contradictory mandate to the young discipline of the history of science. On the one hand, the history of science was charged with explaining modern science to citizens who were not scientists themselves but who would have to make decisions about science policy if democracies were not to become technocracies. Mastering the technicalities of contemporary science was out of the question for most people, but fortunately, modern science since the Scientific Revolution (so went the story) was all of a piece. Instead of learning, say, the latest atomic physics, students majoring in the humanities or social sciences could study the origins of Daltonian atomic theory-or Robert Boyle's pneumatics or the overthrow of phlogiston theory. Conant set forth this rationale in the Harvard Case Histories in the Experimental Sciences (begun in I948), which enshrined the history of science in Harvard's postwar general education requirements:

A direct study of the methods of modern science presents great difficulties. A visitor to a laboratory, unless he is himself a scientist, will find it almost impossible to understand the work in prog- 
ress. ... If one could transport a visitor, however, to a laboratory where significant results were being obtained at an early stage in the history of a particular science, the situation would be far different. For when a science is in its infancy, and a new field is opened up by a great pioneer, the relevant information of the past can be summed up in relatively brief compass. ${ }^{7}$

All modern science was, well, modern, just more or less complicatedand modern science was the only kind worth learning.

On the other hand, many of the founding narratives that twinned the origins of modern science and of modernity tout court were decidedly ambivalent about the modern mentality that had allegedly wrought such seismic transformations. Some accounts celebrated this supernova as a triumph of the human intellect, long overdue. But others-and these were precisely the books that sold best and longest and attracted generations of historians of science to the field-were tinged with melancholy and nostalgia for the Middle Ages, variously imagined as more enchanted, more rational, or more gemütlich than modernity. American philosopher E. A. Burtt intoned a dirge for the "gloriously romantic universe of Dante and Milton, that set no bounds to the imagination of man as it played over space and time" and had been (again, allegedly) "swept away" by Newtonian geometric space and numerical time. ${ }^{8}$ Alexandre Koyré, a Russian emigré who had studied in Göttingen with Husserl and later made his career as an intellectual historian in Paris and Princeton, regarded the transition from "the closed world to the infinite universe" as tantamount to an eviction notice from the purportedly cozy, human-centered medieval cosmos. He was equally elegiac about how Newtonian cosmology had jettisoned "value-concepts, such as perfection, harmony, meaning and aim" and brought about "the utter devalorization of being, the divorce of the world of value and the 
world of facts."9 Alfred North Whitehead, a philosopher whose career straddled both Cambridges, bluntly condemned the science of Galileo, Descartes, and Newton as "anti-rationalistic" compared to the rigorous clarity of medieval philosophy. ${ }^{\text {to }}$ The overall mood was one of clenched-teeth romanticism: there was no reversing modernity; modern science represented a gigantic intellectual leap forward, yet the price paid for progress had been the sacrifice of beauty and a sense of belonging in the universe. Page per page, these narratives contained more stalwart resignation than a Henry James novel.

In addition to instilling nostalgia for premodern science in their readers (who included almost every historian of science of my generation and the one before), these narratives centered the discipline on the Scientific Revolution of early modern Europe. This is when science-and with it, the West-became modern, the greatest worldhistorical transformation "since the rise of Christianity" or even the Neolithic. ${ }^{\text {II }}$ Even though the raison d'être of the new discipline of the history of science was to explain modern science, the focus of scholarly attention was the early modern period-and, inevitably, the preceding period, in order to assess both the causes and magnitude of the changes. The elegiac tone of the discipline's founding narratives enforced respect for the intellectual integrity of premodern systems of thought-as well as for the distinctly unmodern elements of canonical early modern scientific texts (e.g., Kepler's flirtations with Pythagorean number mysticism in the Mysterium cosmographicum or Newton's heterodox theological interpretations of absolute space and time in the Principia mathematica philosophiae naturalis). In contrast to the scientists' own version of their history, recounted as a chronicle of errors overcome and currently accepted doctrines anticipated, historians of science strived to understand past science in its own terms-and as a coherent, albeit exotic intellectual whole. The "modern mentality" was simply one more such thought-world, all- 
encompassing as an atmosphere. All of the early twentieth-century authors who wrote about scientific modernity, and its predecessors struggled to find the right metaphor for such thoroughgoing intellectual phenomena: "frameworks," "worldviews," "worlds of thought" were among their coinages; Kuhnian "paradigms" and Foucauldian "epistemes" were among their descendants. It is no coincidence that Thomas Kuhn and Michel Foucault shared an intellectual grandfather in Alexandre Koyré.

These countervailing tendencies-teleological modernism battling with sympathetic historicism-were already present in Conant's Harvard Case Histories. Conant's own case study of the demise of phlogiston theory is a case in point: the episode had been chosen because it inaugurated modern chemistry, yet Conant refused to tell the story as one of reason victorious over ignorance and superstition, like the archangel Michael planting his foot on the defeated Satan. Instead, he immersed himself in the writings not only of Antoine Lavoisier but also those of Joseph Priestley and other die-hard champions of phlogiston and followed the twists and turns of their thought through a labyrinth of perplexing experimental results. Even the answer to the apparently simple question "Who discovered oxygen?" became a complicated (and fascinating) exploration of the meaning of discovery in Conant's nuanced account. Priestley may ultimately have been wrong to cling to the idea of dephlogisticated air, but after reading Conant's case study, no one could pronounce him thereby irrational. Kuhn (who got his start in the history of science by working on one of Conant's case studies) reported on an analogous epiphany while reading Aristotle in I947:

The more I read [Aristotle's Physics], the more puzzled I became. . . One memorable (and very hot) summer day those perplexities suddenly vanished. I all at once perceived the connected rudiments of an alternative way of reading the texts with which I had been 
struggling. For the first time I gave due weight to the fact that Aristotle's subject was change-of-quality in general, including the fall of a stone and the growth of a child to adulthood. ${ }^{\text {I2 }}$

More than any other single figure, Kuhn was responsible for historicism gaining the upper hand over modernism in the history of science after the I970s. The Structure of Scientific Revolutions (1962) attacked the teleological tendencies of the history of science, denied the doctrine of smooth, continuous scientific progress, directed attention toward contexts and controversies, insisted on the incommensurability of successive scientific thought-worlds, and turned the drab grammatical term "paradigm" into the stuff of New Yorker cartoons. Kuhn's wildly successful book also converted the history of science, a tiny field previously notorious for its musty technicalities ("impetus," "aether," "phlogiston"), into a resource for the humanities, social sciences, and the natural sciences, all of which adapted "paradigms" and "scientific revolutions" (now in the plural) to their own purposes. ${ }^{\text {I3 }}$ In particular, Kuhn's engagement with and challenges to both the sociology and philosophy of science briefly drew these fields to the history of science in search of empirical evidence for how science really worked and, equally briefly, made the history of science the most theorized branch of history, infused with philosophy, sociology, and psychology. Kuhn himself, however, was unwavering in his conviction that history of science belonged in history departments, and that its salvation lay in rejecting the "Whiggishness" so characteristic of the scientists' own version of their past: "For the first time, it [science] has become potentially a fully historical enterprise, like music, literature, philosophy, or law." ${ }^{4}$

Kuhn's elusive but evocative notion of the paradigm provided historians of science bent on extirpating anachronism with a powerful tool: the study of scientific practices-roughly, what scientists actually do as opposed to what they say they do. Because undeniably sci- 
entific practices (e.g., the experiment) could be traced back to what at least from a presentist perspective looked like nonscientific origins (e.g., the artisanal workshop), long-standing methodological quarrels simply faded away. The prolonged wars between internalist and externalist approaches to the history of science ended not with a bang but a whimper, as did the still more acrimonious wars between advocates of realist and social constructionist positions on the nature of scientific knowledge. Scientific practices obviously straddled both camps in both disputes, making further hostilities along those battle lines seem pointless.

Yet the contradiction between modernism and historicism that had imprinted the history of science at birth lingered like a disciplinary neurosis. Historians of science, particularly those most emphatic about adopting the categories of the past to understand the past, fretted endlessly about what they were historians of. For anyone working on the period before circa 1850 (or even thereafter, in languages other than English), it was embarrassingly obvious the word "science" and its cognates in other languages referred to different disciplines and practices (e.g., "the science of history") than the current restrictive usage in English did; that practices now considered unambiguously scientific (e.g., systematic observation of astro-meteorological phenomena) were pursued by people who had nothing to do with the university professors usually singled out as the past counterparts of modern scientists; that the past clustering of disciplines and expertise rarely corresponded to present ones (e.g., the proximity of astronomy to music theory and physics to philosophy in the medieval university curriculum or the high correlation of proficiency in classical philology and botany in the Renaissance); and, most disconcerting of all, that the epistemic virtues enshrined by past forms of scientific inquiry (including that cultivated by heroes such as Galileo or Newton or even Darwin) sometimes diverged sharply from those of present science (e.g., the sine qua non of the Latin scientia was certainty, 
not predictive accuracy; natural philosophy licensed its titularies to indulge in metaphysical speculations now considered strictly taboo among their scientist successors). In a recent collection of a dozen essays commissioned to promote "broad thinking" in the history of science, four were devoted to perplexities about the discipline's subject matter. ${ }^{15}$ Pace the conviction of Conant and his cohort of historians of science that modern science was essentially the same whether pursued by physicists of biologists, at Los Alamos Labs in the twentieth century or in Lavoisier's private laboratory in the eighteenth, even science of the here-and-now revealed itself to be anything but monolithic in methods, modes of explanation, standards of evidence, and, especially, hands-on practices. ${ }^{16}$

Under pressure from the globalized perspective and postcolonial critiques that took the entire discipline of history by storm in the past twenty years, the history of science began to rethink its geography (and chronology) as well as its subject matter. The classical narrative of the history of science was not just a Eurocentric narrative; it was the Eurocentric narrative, the one that explained how the West had outstripped the rest by inventing science and thereby winning the modernity sweepstakes. (What exactly is the connection between the Scientific Revolution and the other components of modernitythe Industrial Revolution, the American and French Revolutions, the demographic transition, secularization, global capitalism, modernism in the arts-has never been precisely spelled out, but that is another story. $)^{\text {I7 }}$

As a glance at the titles of articles published in leading history of science journals in the past two decades reveals, the understanding of what science is and who counts as a scientist has broadened and diversified to include household herbalists, imperial adventurers, women computers, Renaissance bibliographers, Victorian pigeon fanciers, artists depicting the flora and fauna of their native Mexico or India, and many other people lacking white coats, horn-rimmed spec- 
tacles, and a PhD. The sites of science now include not only the laboratory and the observatory, but also the botanical garden, the forge, the library, the field, the ship, and the household hearth. Geography and chronology have also broadened: the Europe (in fact, never more than a few western European countries and then only their leading cities) of the discipline's origins is now dwarfed by a map that embraces at least some parts of all continents and oceans; spectacular recent work on ancient China and Mesopotamia has exploded the discipline's time frame. Almost none of these topics, actors, places, and periods would have qualified as part of the history of science when I was a graduate student in the I970s; all of them have obliged historians of science to rethink their subject matter in mind-stretching ways. If we are no longer historians of modern, Western science (all three words ripe for rethinking) and its analogues and antecedents in other times and places, then what are we historians of?

\section{What Is the History of Knowledge, and Why Should We Care?}

The tentative and still provisional answer is: we are historians of knowledge. This capacious and usefully vague term has the advantage of nipping in the bud sterile, inconclusive discussions about whether Hellenistic alchemy or indigenous Peruvian botany or early eighteenth-century British steam technology is really science-the definition of which has proved to be as elusive as the Holy Grail or the Snark (just ask any philosopher of science). Also, it renders the problematic adjectives "modern" and "Western" superfluous, even if it does not ipso facto place all knowledge on a level. In addition to erasing the vexing (because ill-defined, mobile, and often ideological) boundary between "premodern" and "modern," the ample rubric knowledge licenses historical exploration of all corners of the contemporary mappemonde of the disciplines, embracing the human- 
ities and social sciences as well as the sciences (and turning the translation of Wissenschaft or sciences humaines-or physis or ziran or shizen-from a headache into a research topic). Finally, it allows historians to follow practices wherever they may lead, however remote these may be from anything resembling latter-day science. Even the most audacious studies of science in context have tended to hitch the new practice, site, or actor in question to old stars: the history of experiment is linked to Robert Boyle; the Renaissance court as scientific site to Galileo. ${ }^{18}$ The history of knowledge promises to loosen the hold of canonical people (the pantheon of Aristotle, Copernicus, Kepler, Galileo, etc.) and topics (whatever resembles or leads to modern science).

However, the term has all the vices of its virtues: what doesn't it cover? Its flexibility could easily turn rubbery. For example, the history of knowledge is currently being applied to at least two different and arguably incompatible research programs. One approach wields the term in order to recuperate forms of knowledge that have historically been denigrated as substandard, including the skills of craftsmen; the natural history of hunters, farmers, shepherds, sailors, and other practical experts of the great outdoors; the medical recipes of women and other noncertified healers; and generally the many forms of knowledge cultivated by nonelites in many times and places (often flagged by the prefix "ethno," as in "ethnobotany"). Another approach marching under this banner studies the history of learning (especially philology) and more broadly of the humanities: many (but by no means all) cultures boast impressive traditions of erudition, and some of these (e.g., those devoted to the study of Sanskrit and Latin grammars) have produced regularities as steady as almost any revealed by the natural sciences. Of course these traditions have little in common with those of craftsmen and ethnonaturalists. They are pursued by a tiny, highly educated and socially exclusive elites who emphatically side with the knowledge of the head over that of the hand. 
The only thing these two varieties of the history of knowledge have in common is that they are pointedly not about modern science-but are still implicitly defined by it. One reason is that even those scholars critical of the distortions inherent in the original research program that launched the history of science as a discipline are reluctant to jettison the prestige that still burnishes the terms "modern" and "science." For example, even though scholars are fully aware of how the honorific "modern" has been used to justify colonial conquests, to conjure up scenarios of winner and loser civilizations, and to foster bizarre conflations of Europe's past with other cultures' present, all lumped together as "traditional cultures," they nonetheless cling to the term "modernities," now ecumenically pluralized but still loaded. ${ }^{\text {I9 }}$ It is too precious to discard. The same holds mutatis mutandis for "science"-which is probably why leading Chinese universities insist on establishing programs in the history of science (with an emphasis on Chinese science), not the history of knowledge. They suspect the latter of cultural condescension (roughly on the model of "we have quantum mechanics; you have basket-weaving") and are understandably holding out for the real thing. ${ }^{20}$

Can the history of knowledge be saved? Is it worth saving? The jury's still out, but herewith a few observations to clarify what's at stake. The original disciplinary narrative of the history of science is simply untenable on scholarly grounds, undermined by the careful historicism and aversion to anachronism and teleology that has characterized the most rigorous and imaginative work in the field for the last forty years. There is as yet no single new narrative to take its place. Instead, the field resembles a mosaic of many exquisitely detailed studies of this or that episode, each tessera glinting with color and gold but the heap not pieced together into a larger picture. The study of scientific practices, combined with the enlarged geography and chronology of recent research, has unsettled the most taken-forgranted certainties about both old subjects (e.g., the history of math- 
ematical proof or the origins of heliocentric astronomy ${ }^{2 \mathrm{I}}$ ) and new (e.g., empire and natural history). ${ }^{22}$ Following the trail of practices has intertwined science with its ambient cultural context in tangled ways. There is no way of unweaving this web, of excising science cleanly from other ways of knowing and doing. For all of these reasons, some version of the history of knowledge, of which the history of science is a part, is probably indispensable.

But which version? As it currently stands, the history of knowledge makes a poor showing next to the most conceptually sophisticated examples of the history of science, the latter enriched by decades of stimulating (and sometimes abrasive) interaction with sociology, philosophy, psychology, and science studies. The category of knowledge will have to undergo a similarly probing conceptual analysis, and one that takes a comparative perspective that can do justice to the wealth of materials now on offer in remarkable new studies on epochs and cultures previously marginal to the history of science (and medicine and technology), as well as those produced by the discipline's still thriving core specialties. Such a wide-angle analysis might begin by looking at how classifications and hierarchies of knowledge as well as cardinal epistemic virtues shift over time both within and among cultural traditions. Breadth and unity of knowledge need not go together with quantification; explanation and prediction can exist asunder; precision and communicability sometimes tug in different directions; a desire for ironclad certainty rarely promotes thoroughgoing empiricism. That is the more philosophical aspect of a workable history of knowledge; it is obvious that comparative studies also offer a promising field for sociological, economic, and anthropological inquiry. All cultures cultivate knowledge; all erect a hierarchy of more or less valued forms of knowledge (closely correlated with the social prestige of the knowers)—but not the same forms and the same hierarchies.

Even from a provincially Western, post-seventeenth-century perspective, history supplies plenty of examples of how such hierarchies 
are reordered: botany was the glamorous Big Science of the eighteenth century; classical philology ruled the roost for much of the nineteenth; in the past twenty years genetics has dethroned high energy physics as the queen of the sciences. The form science might well emerge as one interestingly distinct species of the genus knowledge, but it is unlikely to be the only one. Another (and related) species might be the complex "bureaucratic knowledge," that formidable armamentarium of record-keeping, classifying, controlling, and labor-dividing practices that emerges over and over again in different times and places. And even if some historians of science remain preoccupied with the question of what makes science as a way of knowing distinct, the answer presupposes a broad and deep knowledge of other ways of knowing.

Pursued from a cross-cultural and cross-historical perspective, the history of knowledge may well have consequences for our current classifications of knowledge and ways of knowing. The most familiar and most influential classifications of knowledge are the ones that are made concrete in the arrangement of books on library shelves or in the physical organization of buildings on university campuses. These are the classifications that our feet trace day in, day out. They chart the relationships of both literal and figurative distance between disciplines that determine which colleagues we see regularly and which we see hardly ever.

A glance at this typical arrangement of buildings and faculties on almost any university campus confirms what most of us take for granted: mathematics is close to physics, physics and astrophysics occupy the same building, and the music center is very far away from all of them. If this were a medieval university (and if medieval universities had had campuses), astronomy, mathematics, and music would have all been clustered together, as disciplines of the quadrivium, while physics would have been elsewhere, housed with philosophy, the study of universal causes. History, biology, and geology 
would have shared quarters, since all were concerned with particulars (historia, as in both "history" and "natural history"). Nowadays, however, we are not surprised to see that history and literature departments are close to the library, nor that the laboratory sciences flock together as birds of a feather on the opposite side of the campus. Rendered in brick and mortar, in mock Gothic or modernist cubes, these are the classifications of knowledge that guide our steps and our assumptions about what knowledge is-the map of its great continents, its large and small provinces, and the oceans that separate them.

What would this map look like if it were redrawn to reflect shared practices rather than subject matter (currently divided between the realms of the natural and the human)? Some surprising affinities might emerge: the empirical practices of historians and organismic biologists might resemble each other more closely than either resembles philosophy-which in turn might show more analogies with theoretical physics (though not experimental physics). The analysis of variability among texts and among observations in classical philology and astronomy, respectively, exhibits some striking similarities-perhaps because these practices share a common history. ${ }^{23}$ Historical linguistics, philosophy of science, and behavioral economics all make use of the techniques of Bayesian probability, and the algorithms that drive internet search engines are simply the venerable humanist methods of compiling citations and concordances on steroids. ${ }^{24}$ None of this implies that the current division of the academic landscape into the natural sciences, the social sciences, and the humanities is groundless; only that it is neither inevitable nor without alternatives. The advantage of studying knowledge practices is not to erase all distinctions but rather to query the necessity of the ones we have-and to imagine others based on criteria closer to how disciplines actually conduct inquiry.

To realize this vision of the history of knowledge would also require changes in how the history of science itself conducts inquiry. 
Like most humanists, we work in splendid solitude, producing individually authored books and articles. Like all scholars, we try to take account of the relevant secondary literature, but "relevant" is often implicitly circumscribed by extant specialties and periodizations and still more by the languages we can read. It is clear that a history of knowledge conducted comparatively and on a greatly enlarged geographic and chronological scale necessitates more collaborative efforts. No single scholar, no matter how erudite and diligent, can hope to cover this waterfront alone. Nor will the usual conference volume, with articles devoted to a spectrum of case studies on various places and periods suffice. Comparison requires conversation; integration of comparisons into a coherent picture requires still more conversation, and on a sustained basis. This is a very different and considerably more strenuous collaborative model than the multiauthored scientific article: the latter depends on a clear-cut division of labor; the former on overcoming the division of labor. The one is practiced in the name of efficiency; the other will undoubtedly be maddeningly meandering, at least in its early stages.

Can we change our own ways of knowing in the ways that would make a worthwhile history of knowledge possible? The odds are probably against it: by temperament and training we are happiest when left alone to read, think, and write; evaluation procedures reinforce these individualistic tendencies at every turn; we associate long, open-ended discussions with the dreariest sort of faculty meeting. Most importantly, the history of science is flourishing, not only by its own standards but also as measured by the attention it increasingly receives from scholars in other disciplines. When I was a graduate student, the quickest way to find yourself all alone at an academic cocktail party was to announce that you were a historian of science; nowadays your interlocutor is likely to have read one or two landmark studies in the field and take it for granted that your current project will be accessible and worth hearing about. Inso- 
far as any discipline spans the natural sciences, social sciences, and humanities in terms of both subject matter and methods, it is the history of science. So why tamper with success?

There are two compelling reasons to do so. The first is that we are in the uncomfortable position of teaching our students a narrative that we know is gravely flawed if not outright false, as shown by three decades of the best research in the field. The first ironic sentence of an influential undergraduate textbook encapsulates this predicament: "There was no such thing as the Scientific Revolution, and this is a book about it." ${ }^{25}$ Analogous soul-searching is going on in other specialties: medievalists point out that the traditional division between "Latin" and "Muslim" science is nonsensical when referring to intellectual traditions with common origins and countless exchanges (not to mention the incoherence of opposing a language to a religion); ${ }^{26}$ historians of science and empire argue that it is the essence of natural knowledge to be in circulation among cultures, on explicit analogy with commodities. ${ }^{27}$ As every teacher of undergraduate survey courses knows, it won't do to bombard students with the latest studies that debunk the old narrative about the birth of modern Western science if there's no new narrative to put in its place-and one that is just as sweeping and memorable as the old one. That is one urgent reason to undertake the arduous synthesis that a genuine history of knowledge would require.

The second is that our originary disciplinary neurosis has spread far beyond our discipline. Even if we historians of science handle phrases such as "modern Western science" with tongs and punt on the question of exactly what we are historians of, the world at large observes no such niceties. And I do mean the world at large: the image of science and modernity as a race of civilizations, in which there are losers and winners, has overflowed the academic lecture hall. When Narendra Modi, currently prime minister of India, gives speeches in which he claims that the Hindu god Rama flew in an airplane be- 
tween planets or that cosmetic surgery was practiced in ancient India (how else could the head of an elephant be affixed to a human body?), ${ }^{28}$ he is inadvertently paying tribute to the very Western standards he claims to disdain as a Hindu nationalist. Nor is this an isolated example of confabulating a glorious scientific past, anticipating everything from the internal combustion engine to general relativity theory, in order to salve wounded national pride. ${ }^{29}$ Nobody wants to be left behind in the race to scientific modernity, an image the history of science created and long embellished. In this wider context, the originary narrative of the history of science is not only false but also dangerous. Once again, a swarm of specialist refutations of this or that aspect of the old narrative is unlikely to make any impression. A new narrative that makes sense of the efflorescence of new specialist research is needed, and once again some version of the history of knowledge that goes beyond the equation "knowledge equals everything that is not modern science" seems the most promising candidate.

This is the point where double vision ought to resolve: the history of science would change its disciplinary ways of knowing in order to understand what knowledge is. I don't know whether it is possible for the history of science to escape from its hall of mirrors, or whether the attempt would just worsen the vertigo. But we can't just go on as before. 


\section{Notes}

I. For brief overviews of the history of the history of science, see Lorraine Daston, "Science, History of," in International Encyclopedia of the Social and Behavioral Sciences, ed. James D. Wright (Oxford: Elsevier, 20I5), 2I:24I-47; and, on more recent trends, Robert E. Kohler and Kathryn M. Olesko, eds., introduction to Clio Meets Science: The Challenges of History (Chicago: University of Chicago Press, 20I2), I-I6.

2. Alfred North Whitehead, Science and the Modern World (New York: Macmillan, I925; 45 printings I925-2008; at least 30 translations); Herbert Butterfield, The Origins of Modern Science, 1300-1800 (London: G. Bell, I949; 33 printings I94920I3; at least I3 translations). Both books are still in print.

3. In addition to Whitehead and Butterfield, other classics of the genre include E. A. Burtt, The Metaphysical Foundations of the Modern Physical Sciences (I924; rev. ed., I932; 30 printings I924-20I4), and Alexandre Koyré's Études galiléennes (I940) and especially his From the Closed World to the Infinite Universe (I957; I4 English printings and I5 French, I957-20I I). All of these books are also still in print, with multiple translations into many European and several Asian languages. In German, Edmund Husserl's Die Krisis der europäischen Wissenschaft und die transzendentale Phänomenologie (comp. 1935-37; posthumously published in I954) also belongs in this group, but its publication and reception history is more complicated. However, Husserl's views on Galileo and the modern mentality were widely diffused through his student Koyré's publications long before Husserl's own lectures saw the light of print.

4. Herbert Butterfield, The Origins of Modern Science, 1300-1800 (New York: Free Press, I957), 7.

5. A. N. Whitehead, Science and the Modern World (New York: Free Press, I967), 3.

6. W. W. Rostow, The Stages of Economic Growth: A Non-Communist Manifesto (Cambridge: Cambridge University Press, I960), 5. 
7. James Bryant Conant, introduction in Harvard Case Histories in Experimental Science, ed. James Bryant Conant and Leonard K. Nash, 2 vols. (Cambridge, MA: Harvard University Press, I970), I:vii-xvi, at viii.

8. E. A. Burtt, The Metaphysical Foundations of Modern Physical Science (New York: Doubleday, I954), 238.

9. Alexandre Koyré, From the Closed World to the Infinite Universe (Baltimore: Johns Hopkins University Press, 1957), 2.

Io. Whitehead, Science and the Modern World, I6.

I I. Butterfield, Origins of Modern Science, 202; David Wootton, The Invention of Science: A New History of the Scientific Revolution (Milton Keynes: Allen Lane, 20I5), 3.

I2. Thomas Kuhn, The Essential Tension: Selected Studies in Scientific Tradition and Change (Chicago: University of Chicago Press, I977), xi.

I3. On the broad and lasting influence of Kuhn's book, see Robert J. Richards and Lorraine Daston, eds., Kuhn's "Structure of Scientific Revolutions" at Fifty: Reflections on a Science Classic (Chicago: University of Chicago Press, 2016).

I4. Thomas S. Kuhn, "The Relations between History and the History of Science," originally published in Daedalus I00 (I97I): 27I-304, and reprinted in Thomas S. Kuhn, Essential Tension, I27-6I, at I50.

I5. Kohler and Olesko, Clio Meets Science. The essays in question were Jan Golinski, "Is It Time to Forget Science? Reflections on Singular Science and Its History," I9-26; Peter Dear, "Science Is Dead; Long Live Science," 37-55; Paul Forman, "On the Historical Forms of Knowledge Production and Curation: Modernity Entailed Disciplinarity, Postmodernity Entails Antidisciplinarity," 59-67; Edward Grant, "Reflections of a Troglodyte Historian of Science," I33-55; and Lynn K. Nyhart, "Wissenschaft and Kunde: The General and the Special in Modern Science," 250-75.

I6. Peter Galison and David Stump, eds., The Disunity of Science: Boundaries, Contexts, and Power (Stanford, CA: Stanford University Press, I996).

I7. The connection is nonetheless asserted or assumed by almost every social scientific account of modernization. See, e.g., the articles in Malcolm Waters, ed., Modernity: Critical Concepts, 4 vols. (London: Routledge, I999), esp. vol. I, Modernization. For a recent historical attempt to argue the case, at least for the Industrial Revolution, see Wootton, Invention of Science, 43I-48, 476-508.

I8. Steven Shapin and Simon Schaffer, Leviathan and the Air Pump: Hobbes, Boyle, and the Experimental Life (Princeton, NJ: Princeton University Press, 1985); Mario Biagioli, Galileo, Courtier: The Practice of Science in the Culture of Absolutism (Chicago: University of Chicago Press, 1993). 
I9. See, e.g., Dipesh Chakrabarty, Habitations of Modernity: Essays in the Wake of Subaltern Studies (Chicago: University of Chicago Press, 2002); Huri Islamoglu and Peter Perdue, eds., Shared Histories of Modernity: China, India, and the Ottoman Empire (London: Routledge, 2009).

20. Dagmar Schäfer, "Frames of Reference in the History of Science: China and the Rest," paper prepared for the roundtable "History of Science in a World of Readers," History of Science Society annual meeting, November 4, 2016, Atlanta. I am grateful to Professor Schäfer for several illuminating conversations about the history of science in China.

2I. Karine Chemla, ed., The History of Mathematical Proof in Ancient Traditions (Cambridge: Cambridge University Press, 20I2); F. Jamil Ragep, "Ibn al-Shatir and Copernicus: The Uppsala Notes Revisited," Journal of the History of Astronomy 47 (20I6): 395-4I5.

22. Londa Schiebinger and Claudia Swan, eds., Colonial Botany: Science, Commerce, and Politics in the Early Modern World (Philadelphia: University of Pennsylvania Press, 2005); Fa-ti Fan, British Naturalists in Qing China: Science, Empire, and Cultural Encounter (Cambridge, MA: Harvard University Press, 2004); Daniela Bleichmar, Visible Empire: Botanical Expeditions and Visual Culture in the Hispanic Enlightenment (Chicago: University of Chicago Press, 2012).

23. Lorraine Daston and Glenn W. Most, "The History of Science and the History of Philologies," Isis I06 (2015): 378-90.

24. Daniel Rosenberg, "An Archive of Words," in Science in the Archives: Pasts, Presents, Futures, ed. Lorraine Daston (Chicago: University of Chicago Press, 2017), 27I-3IO.

25. Steven Shapin, The Scientific Revolution (Chicago: University of Chicago Press, I996), I.

26. Katharine Park, "Rethinking the History of Western Science Narrative, Translation, and the Longue Durée," http://www.einsteinforum.de /veranstaltungen/rethinking-the-history-of-western-science-narrative -translation-and-the-longue-duree/. Rivka Feldhay and F. Jamil Ragep, eds., Before Copernicus: The Cultures and Contexts of Scientific Learning in the Fifteenth Century (Kingston: McGill-Queen's University Press, 2017).

27. James Secord, "Science in Transit," Isis 95 (2004): 654-72; Harold J. Cook, Matters of Exchange: Commerce, Medicine, and Science in the Dutch Golden Age (New Haven, CT: Yale University Press, 2007); Kapil Raj, Relocating Modern Science: Circulation and the Construction of Knowledge in South Asia and Europe, 1650-1900 (New York: Palgrave Macmillan, 2007); Simon Schaffer, Lissa Roberts, Kapil Raj, and 
James Delbourgo, eds., The Brokered World: Go-Betweens and Global Intelligence, 1770-1820 (Sagamore Beach, MA: Science History Publications, 2009).

28. "Indian Prime Minister Claims Genetic Science Existed in Ancient Times," The Guardian, October 28, 20I4, http://www.theguardian.com/world/20I4/oct/28 /indian-prime-minister-genetic-science-existed-ancient-times.

29. Sonja Brentjes, Edis Tanner, and Lutz Richter-Bernberg, eds., 1001 Distortions: How (Not) to Narrate the History of Science, Medicine, and Technology in NonWestern Cultures (Würzburg: Ergon-Verlag, 20I6). 